\title{
Comparison of radiographic changes of the proximal third metacarpal and metatarsal bones in horses with and without proximal suspensory desmitis
}

\author{
Marc Trump' , Elena Siegenthaler', Patrick R. Kircher ${ }^{2}$, Anton Fürst ${ }^{\prime}$ and Felix Theiss ${ }^{3,1}$ \\ 1 Equine Hospital, Vetsuisse Faculty, University of Zurich, Winterthurerstrasse 260, 8057 Zurich, Switzerland \\ 2 Section of Diagnostic Imaging, Vetsuisse Faculty, University of Zurich, Winterthurerstrasse 260, 8057 Zurich, Switzerland \\ 3 Centre for Applied Biotechnology and Molecular Medicine, Vetsuisse-Faculty, University of Zurich, Winterthurerstrasse 190,8057 Switzerland
}

\begin{abstract}
Summary: Medical records of horses examined from 1994 to 2011 at the Equine Hospital, Vetsuisse Faculty, University of Zurich, because of proximal suspensory desmitis (PSD) were reviewed. Radiographic changes visible on dorsopalmar and dorsoplantar projections of the proximal third metacarpal/metatarsal bone (MCIII/MTIII) were analysed with respect to localisation, degree of increased radiopacity, length, width and pattern of radiopacity in relation to sex, age, breed, duration and degree of lameness and affected limb of the horses. Results were compared with those from sound control horses. Horses with PSD had increased radiopacity, which was significantly more prevalent medially than laterally in the forelimbs $(p<0.05)$ and more prevalent laterally than medially in the hindlimbs $(p<0.05)$. The width of the area of increased radiopacity was significantly greater in the forelimbs than in the hindlimbs $(p<0.05)$. The pattern of increased radiopacity was diffuse in 102 (85.7\%) horses and multifocal in the remaining $17(14.3 \%) .35 .3 \%(n=6)$ of multifocal changes were detected on one of the front limbs, whereas $74.7 \%(n=11)$ were diagnosed on the hind limbs. Mildly increased diffuse radiopacity, with a distribution pattern comparable to cases with PSD was detected in 15 of 60 control horses. In comparison to control cases, the degree of increased diffuse radiopacity was significant more pronounced in horses with PSD $(p<0.001)$. The multifocal pattern of increased radiopacity could not be detected in any of the control horses. The results aid in the interpretation of radiographic changes seen in horses with PSD. Whereas a diffuse increased radiopacity of the proximal MCIII/MTIII needs to be interpreted with caution, as a mild degree may be seen in sound horses, the multifocal distribution pattern seems to be unique feature of horses with PSD.
\end{abstract}

Keywords: proximal suspensory desmitis / PSD / radiographic changes / suspensory ligament / desmitis

\section{Vergleich von röntgenologischen Veränderungen im Bereich des proximalen Metakarpus und Metatarsus bei Pferden mit} und ohne Desmopathie des Fesselträgerursprungs

\begin{abstract}
In der vorliegenden Studie wurden die Patientendaten von Pferden, die im Zeitraum von 1994 bis 2011 in der Pferdeklinik des Departements für Pferde der Vetsuisse-Fakultät, Universität Zürich wegen einer Desmitis des Fesseltägerursprungs vorgestellt wurden, retrospektiv evaluiert. Die im dorso-palmaren, bzw. dorso-plantaren Strahlengang sichtbar vermehrte Röntgendichte im Bereich des proximalen Metakarpus III/Metatarsus III wurde nach ihrer Lokalisation, Ausdehnung (Länge und Breite), Schweregrad der Veränderungen und Erscheinungsbild ausgewertet. Zudem wurden das Geschlecht, das Alter, die Rasse, die Dauer der klinischen Symptomatik, die erkrankte Gliedmaße und der Lahmheitsgrad ausgewertet. Die Ergebnisse wurden mit einer Kontrollgruppe verglichen. Für die Kontrollgruppe wurden 30 Röntgenbilder eines Karpus und 30 Röntgenbilder eines Tarus je in der dorsopalmaren/plantaren Projektion nach dem gleichen Schema ausgewertet, wie die an Fesseltägerursprungsdesmitis erkrankten Pferde. Die Pferde der Kontrollgruppe waren frei von Lahmheit. An den Vordergliedmaßen waren die Bereiche mit vermehrter Röntgendichte signifikant $(p<0.05)$ häufiger medial und an den Hintergliedmaßen signifikant $(p<0.05)$ häufiger lateral. Die Breite der vermehrten Röntgendichte war an den Vordergliedmaßen signifikant $(p<0.05)$ größer als an den Hintergliedmaßen. Das Verteilungsmuster der Bereiche mit erhöhter Röntgendichte war bei $85.7 \%$ der Fälle diffus und in 14.3\% mutifokal. 35.3\% ( $n=6)$ der multifokalen Veränderungen wurden an der Vordergliedmaße und $74.7 \%(n=11)$ an der Hintergliedmaße diagnostiziert. Bei 15 der 60 Pferde aus der Kontrollgruppe (25\%) konnte eine leichtgradig ausgeprägte, diffus vermehrte Röntgendichte, bei ähnlichem Verteilungsmuster wie bei den an einem PSD erkrankten Pferden beobachtet werden. Der Grad der röntgenologischen Veränderungen war bei Pferden der PSD Gruppe signifikant größer im Vergleich zu Pferden der Kontrollgruppe $(p<0.001)$. Das multifokale Verteilungsmuster der erhöhten Röntgendichte konnte bei keinem Pferd der Kontrollgruppe beobachtet werden. Die Ergebnisse der vorliegenden Studie zeigen einen guten Zusammenhang zwischen der Anatomie des Fesselträgerursprungs und dem Verteilungsmuster der röntgenologischen Veränderungen. Da leichtgradige, diffuse röntgenologische Veränderungen auch bei Pferden zu finden sind, die nicht an einer Desmitis des Fesselträgerursprungs leiden, müssen Röntgenbilder des proximalen Röhrbeins von Pferden mit Verdacht auf Desmitis des Fesseltägerursprungs mit Vorsicht interpretiert werden.
\end{abstract}

Schlüsselwörter: Fesselträgerursprung / Desmopathie / Ursprungsdesmopathie / röntgenologische Veränderungen / röntgenologische Untersuchung / Fesselträger / Desmitis

Citation: Trump M., Siegenthaler E., Kircher P. R., Fürst A., Theiss F. (2014) Comparison of radiographic changes of the proximal third metacarpal and metatarsal bones in horses with and without proximal suspensory desmitis. Pferdeheilkunde 30, 671-676

Correspondence: Dr. Marc Trump, Equine Hospital, Vetsuisse Faculty University of Zurich, Winterthurerstrasse 260, 8057 Zurich, Switzerland. E-mail: marc.trump@gmail.com

\section{Introduction}

Lesions of the proximal suspensory ligament are a common cause of lameness in performance as well as pleasure horses (Gibson et al. 2002, Gomez 2003, Trump et al. 2014) and are thought to be the result of acute or chronic repetitive trauma. Degenerative processes may also play a role in PSD (Kold et al. 2011, Mero et al. 2002, Mero et al. 2005). In addition to diagnostic nerve blocks, diagnosis of PSD involves the use of imaging modalities such as ultrasonography, radio- 
graphy, scintigraphy, computed tomography (CT) or magnetic resonance imaging. Ultrasonography is commonly used to examine the suspensory ligament but interpretation of results is somewhat subjective and the technique is prone to a variety of artefacts (Dyson 2003, Zauscher et al. 2013). On radiographs the principal changes seen at the origin of the suspensory ligament on dorsopalmar/dorsoplantar views are increased radiopacity of the proximal MCIII/MTIII, which is compatible with new bone formation at the origin of the fibres of the suspensory ligament and enthesophyte formation at the palmar/plantar aspect of the cannon bone (Dyson 2011, Dyson et al. 1995, Dyson et al. 2012). Dorsopalmar/dorsoplantar views often show changes in radiopacity at the origin of the suspensory ligament in chronically lame horses, but these changes are rare in acute cases, and much more frequent in hindlimbs than in forelimbs (Dyson 2003, Dyson et al. 1995, Gomez 2003). Despite of this, increased radiopacity of the proximal MCIII/MTIII had been described in normal horses (Butler et al. 2008). Other radiographic abnormalities include alterations in the trabecular pattern of the proximal palmar/plantar region of the cannon bone, and enthesophyte formation seen in lateromedial projections (Dyson 1994).

There are anatomical differences between the suspensory ligament of the fore- and hindlimb. In the forelimb, the origin is bilobed in cross-section. The medial part is rectangular with a greater craniocaudal than laterolateral dimension. The lateral portion is thicker than the medial portion, is wider axially than abaxially and only adopts a rectangular cross-section further distally (Nagy et al. 2009). In the hindlimb, the bilobed structure of the origin of the suspensory ligament is indistinct and the ligament is oval in cross-section and positioned slightly laterally along the plantar aspect of the cannon bone (Bischofberger et al. 2006).

Based on these anatomical differences, we hypothesised that the radiographic pattern of increased radiopacity at the origin of the suspensory ligament in horses with PSD differs in the fore- and hindlimb, and that structural radiographic changes are predominantly in the middle and medial parts of the proximal MCIII and predominantly in the lateral part of the proximal metatarsal bone. Despite this, we hypothesiesed, that radiographic changes found in horses with PSD are more severe than those, which can be found in sound horses.

\section{Materials and Methods}

The medical records of horses examined from 1994 to 2011 at the Equine Hospital, Vetsuisse Faculty, University of Zurich, because of PSD were reviewed. In total, 266 horses had been presented with PSD. Inclusion criteria were a positive response to a diagnostic nerve block of the origin of the suspensory ligament (high palmar/plantar analgesia and lateral palmar/plantar nerve block), the availability of positive results of ultrasonographic examination or a positive scintigraphic examination and changes in dorsopalmar/dorsoplantar radiographic views of the proximal MCIII/MTIII. Radiographs were evaluated independently by two of the authors (MT and ES). When interpretation of the radiographs differed, the two evaluators were assisted by a board certified radiologist (PK) who independently evaluated the radiographs and made the final diagnosis. Sex, age and breed of the horse, duration of lame- ness, limb affected and degree of lameness were also analysed. The horses were allocated to four age groups ( $<4$ years, 4 to 8 years, 9 to 15 years, $>15$ years) and grouped as warmblood, thoroughbred, draft, Icelandic and quarter horses, ponies and other breeds. Use of the horses was classified as pleasure, jumping, dressage, racing, western riding, eventing, endurance riding, vaulting and polo. The duration of lameness was categorized as $\leq 2$ days (peracute), 3 to 14 days (acute), 15 to 28 days (subacute) and $>28$ days (chronic). The degree of lameness was scored from 1 to 5 (AAEP 1991). Increased radiopacity at the proximal MCIII/MTIII seen in dorsopalmar/dorsoplantar radiographic projections was analysed according to localisation, degree of increased radiopacity, size (length and width) and pattern. The localisation of increased radiopacity was defined relative to the median of the proximal MCIII/MTIII using seven categories shown in Fig. 1; there were two evenly-spaced reference points in the lateral and medial third and three reference points in the middle third of the palmar/plantar aspect of the cannon bone. The width (horizontally) and length (vertically) of the radiopacity were expressed in terms of the width of the proximal MCIII/MTIII at the level of the carpometacarpal and tarsometatarsal joints. The maximum width of radiopacity was expressed as $<1 / 3,1 / 3$ to $2 / 3$ and $>2 / 3$ of the width of the proximal MCIII/MTIII, and the maximum length, measured from the joint gap to the distal-most point of increased radiopacity, was expressed as $<0.5,0.5$ to $1.0,1.0$ to 1.5 and $>1.5$ times the width of the proximal MCIII/MTIII. Depending on the distribution, the pattern of increased radiopacity was defined as diffuse or multifocal (Fig. 2). Diffuse increased radiopacity had an even distribution across the entire affected area of bone whereas multifocal radiopacity had small areas of increased and decreased opacity. Horses with ultrasonographic evidence of mineralisation of the suspensory ligament

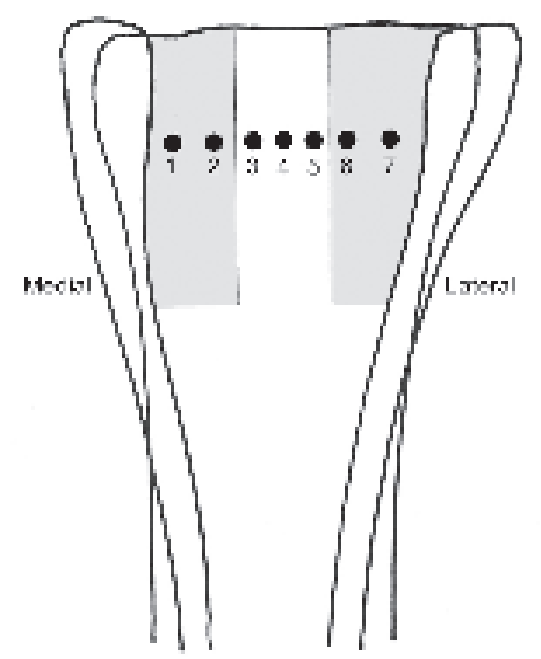

Fig. 1 Schematic depiction of the palmar/plantar aspect of the proximal cannon bone showing the seven categories used to define the localisation of increased radiopacity. The dots mark the centres of the localisations. 1 medial; $2>50 \%$ medial; $3<50 \%$ medial; 4 middle; $5<50 \%$ lateral; $6>50 \%$ lateral; 7 lateral / Schematische Zeichnung des palmaren/plantaren Bereiches des proximalen Röhrbeins. Einteilung der verschiedenen Kategorien zur Lokalisation der Sklerosierung. Der Punkt markiert das jeweilige Zentrum. 1: medial; 2: medial $>50 \%$; 3 : medial $>50 \%$; 4 : Mitte; 5 :lateral $<50 \%$; 6 : lateral $>50 \%$; 7 : lateral 
at the level of the proximal MCIII/MTIII were excluded from the study. Lysis was defined as areas with reduced opacity at the proximal MCIII/MTIII, and fissure fractures in that region were also noted. Thirty dorsopalmar radiographic views of the proximal MCIII and 30 dorsoplantar views of the proximal

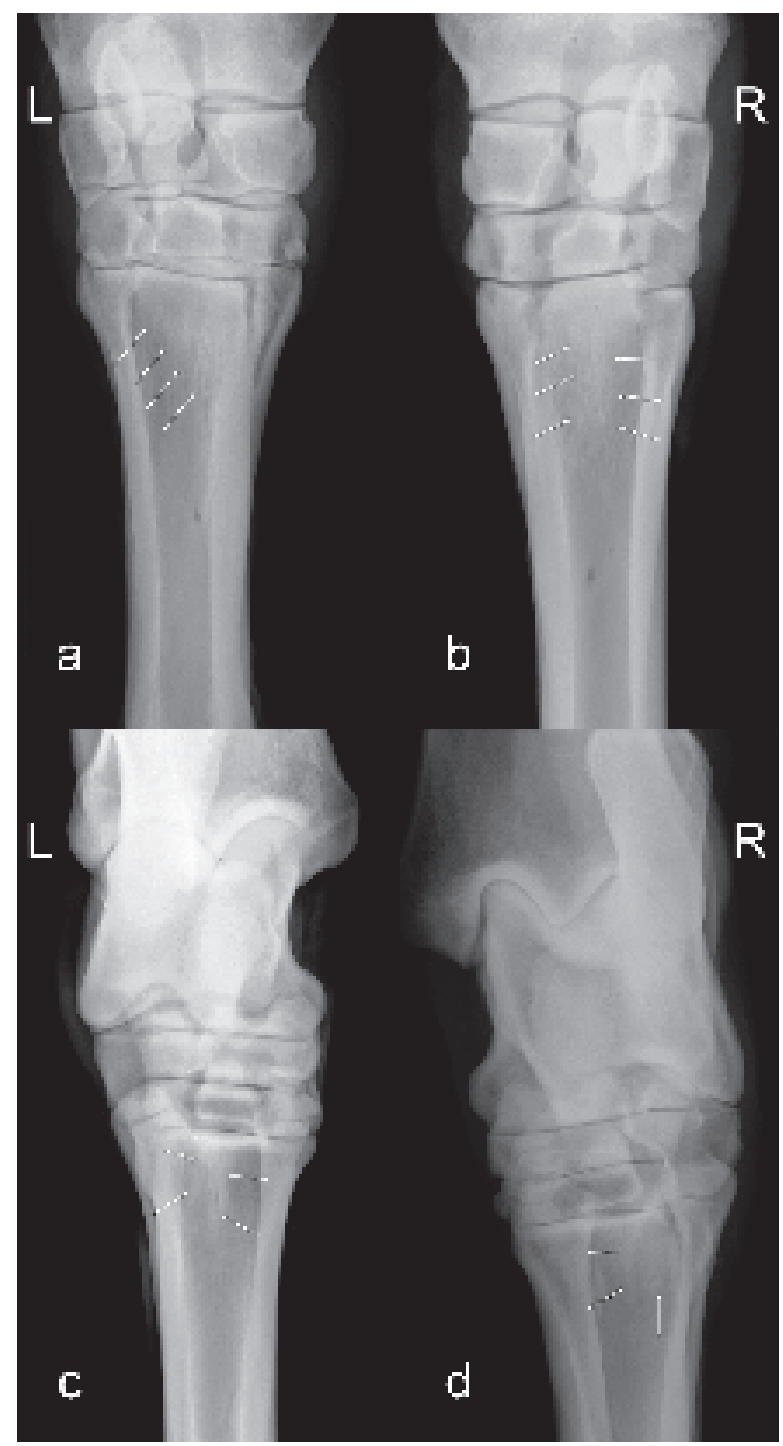

Fig. 2 Typical patterns of radiopacity in the fore- and hindlimb. Forelimb with diffuse (a) and multifocal increased radiopacity (b). Hindlimb with diffuse (c) and multifocal (d) increased radiopacity; Arrows outline the increased radiopacity. / Darstellung der verschieden Sklerosemuster an der Vorder- und Hintergliedmaße: Vordergliedmasse mit diffus erhöhter Röntgendichte (a) und multifokal erhöhter Röntgendichte (b). Hintergliedmaße mit diffus erhöhter Röntgendichte (c) und multifokal erhöhter Röntgendichte (d). Die Pfeile zeigen die Ränder der vermehrten Röntgendichte.
MTIII obtained from 60 sound control horses were used for comparison.

Statistical calculations were completed using Stata (StataCorp LP, Texas, USA). Relationships between the aforementioned variables and the occurrence of radiographic changes related to PSD were examined using the chi-square test for association, or Fisher's exact test if the sample size was $<5$. A Pvalue $\leq 0.05$ was considered significant.

\section{Results}

The records of 119 horses met the inclusion criteria. There were 63 (52.9\%) geldings, 44 (37.0\%) mares and 12 (10.1\%) stallions. The mean age was 10.6 years (median, 10 years; range, 2 to 25 years); 58 were nine to 15 years of age, 45 were four to eight years, 15 were older than 15 years and one horse was younger than four years of age. Horses with PSD in a forelimb were on average 10.1 years old (median, 9.5 years; range 2 to 25 years) and horses with hindlimb PSD were on average 11.0 years old (median, 10 years; range 5 to 23 years). The two predominant breed categories were warmblood ( $n=81,68.1 \%)$ and other $(n=18,15.1 \%)$. Twenty-nine (24.4\%) were used for jumping, 18 (15.1\%) for dressage, 26 (21.9\%) for pleasure and in 37 (31.1\%) horses, the use was not recorded. Hindlimb PSD occurred in 63 $(52.9 \%)$ horses and forelimb PSD in 56 (47.1\%). Grade 2 lameness was recorded in 32 (26.9\%) horses and grade 3 lameness in 75 (63.0\%). Horses with forelimb desmitis had significantly lower lameness scores than horses with hindlimb desmitis $(p<0.05$, Table 1).

The duration of lameness was documented in 103 horses and was longer than 28 days in 70 (68.0\%) horses. In 33 (32.0\%) of the 103 horses, the lameness was peracute $(n=3)$, acute $(n=19)$ or subacute $(n=11)$.

Of the 58 horses nine to 15 years of age, 35 (60.3\%) had hindlimb PSD, whereas of the 45 horses four to eight years old, 24 (53.3\%) had forelimb PSD. The various breeds did not differ with respect to whether the fore- or hindlimb was affected. With respect to use, jumpers were the only horses with a trend for the hindlimb to be more frequently affected than the forelimb (19 versus 10).

\section{Evaluation of radiographs}

Increased radiopacity was mild in $56.3 \%$, moderate in $37.0 \%$ and severe $6.7 \%$. Severity of increased radiopacity

\begin{tabular}{lcc}
\hline Table 1 & Lameness scores in horses with fore- and hindlimb proximal suspensory desmitis & \\
\hline Score* & Forelimb $(\mathrm{n}=56)$ & Hindlimb $(\mathrm{n}=63)$ \\
\hline $1 / 5$ & 1 & 1 \\
$2 / 5$ & 23 & 9 \\
$3 / 5$ & 29 & 46 \\
$4 / 5$ & 3 & 5 \\
$5 / 5$ & 0 & 0 \\
Not recorded & 0 & 2 \\
\hline
\end{tabular}

* AAEP (ref. 16) 
was not statistically correlated with duration of lameness, grade of lameness and pattern of radiopacity.

Increased radiopacity was significantly more prevalent medially than laterally in the forelimbs, whereas in the hindlimbs, there was significantly more radiopacity laterally (both $p<0.05$; Fig. 3, Table 2). The width of increased radiopacity was significantly greater in the forelimbs than in the hindlimbs $(p<0.05$; Table 3). In 40 horses (71.4\%) with forelimb PSD, the width of increased radiopacity was $1 / 3$ to $2 / 3$ the width of the proximal MCIII and in seven horses (12.5\%), it was less than $1 / 3$ the width of the bone. In 30 horses (47.6\%) with hindlimb PSD, the width of increased radiopacity was $1 / 3$ to $2 / 3$ the width of the proximal MCIII and in 31 horses (49.2\%), it was less than $1 / 3$ the width of the bone. The length of increased radiopacity did not differ between fore- and hindlimbs. Increased radiopacity was diffuse in 102 horses $(85.7 \%)$ and multifocal in 17 horses (14.3\%). Of the latter, six (35.3\%) had forelimb and the remaining 11 (64.7\%) had hindlimb suspensory desmitis, whereas diffuse increased radiopacity was diagnosed in $49.0 \%$ of the forelimbs and in $51.0 \%$ of the hindlimbs. In four

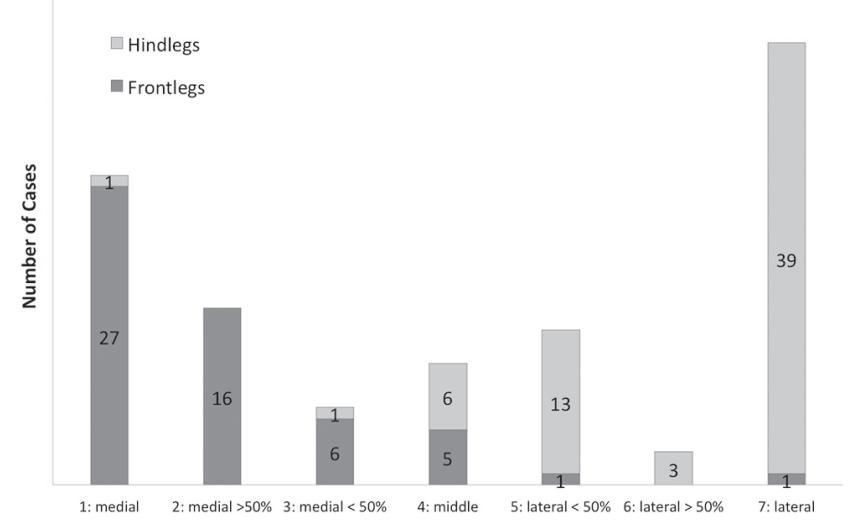

Fig. 3 Localisation of increased radiopacity in the proximal $\mathrm{MCl}$ II/MTIII of horses with proximal suspensory desmitis / Lokalisation der erhöhten Röntgendichte am proximalen MCIII/MTIII bei Pferden mit Desmitis des FTU horses $(3.4 \%)$, there was a focal decrease in opacity at the proximal MCIII/MTIII consistent with an avulsion fracture. Fissure fractures of the proximal cannon bone were more common in the forelimb $(n=7)$ than in the hindlimb $(n=1$; $p<0.05)$

\section{Control Group}

In the control group, $25.0 \%(n=15)$ of the horses had increased radiopacity in the proximal MCIII/MTIII (Table 2). As in the PSD group, increased radiopacity was more prevalent medially than laterally in the forelimbs, and in the hindlimbs, there was more opacity laterally. Radiopacity detected in the 15 control horses was always mild and diffuse. The prevalence of increased radiopacity in the proximal cannon bone was significantly more common in the PSD group than in the control group $(p<0.05)$. Moderate and severe lesions were significantly more often in the PSD group $(p<0.001)$. The mean age of the controls was 10.1 years (median 9 years; range 2 to 23 years). Horses with increased radiopacity at the proximal cannon bone had a mean age of 10.2 years (median 9 years; range 3 to 23 years) and horses without increased opacity had a mean age of 9.6 years (median 9 years; range 2 to 23 years).

\section{Discussion}

Increased radiopacity associated with PSD was located medially at the proximal cannon bone in 27 of 56 horses (48.2\%) affected in a forelimb and laterally at the proximal cannon bone in 39 of 63 horses (61.9\%) affected in a hindlimb. The patterns of increased radiopacity were characteristic and differed significantly between fore- and hindlimbs. The area of increased radiopacity was wider in the forelimb than in the hindlimb. The dissimilarities in the pattern of radiopacity between fore- and hindlimbs can be explained by anatomical differences in the origin of the suspensory ligament; the origin extends across almost the entire width of MCIII, but is slightly

Table 2 Localisation of radiographic opacity in fore- and hindlimbs of horses with proximal suspensory desmitis; numbers in brackets refer to the control group / Lokalisation der erhöhten Röntgendichte in Bezug auf die erkrankte Gliedmaße; In Klammern die Werte der Kontrollgruppe

\begin{tabular}{|c|c|c|}
\hline Category/ Localisation of sclerosis & Forelimb $n=56(6)$ & Hindlimb $n=63(9)$ \\
\hline $1:$ medial & $27(0)$ & $1(0)$ \\
\hline 2: $>50 \%$ medial & $16(6)$ & $0(0)$ \\
\hline 3: $<50 \%$ medial & $6(0)$ & $1(0)$ \\
\hline 4: middle & $5(0)$ & $6(3)$ \\
\hline 5: $<50 \%$ lateral & $1(0)$ & $13(5)$ \\
\hline $6:>50 \%$ lateral & $0(0)$ & $3(0)$ \\
\hline 7: lateral & $1(0)$ & $39(1)$ \\
\hline
\end{tabular}

Table 3 Width of increased radiopacity relative to the entire width of the proximal third metacarpal/metatarsal bone in fore- and hindlimbs of horses with proximal suspensory desmitis; numbers in brackets refer to the control group. / Breite der erhöhten Röntgendichte in Bezug auf die Breite des prox. MCIII/MTIII und die erkrankte Gliedmaße; in Klammern die Werte der Kontrollgruppe

\begin{tabular}{lcc}
\hline Width of sclerosis & Forelimb $\mathrm{n}=56(6)$ & Hindlimb $\mathrm{n}=63(9)$ \\
\hline$<1 / 3$ & $7(0)$ & $31(7)$ \\
$1 / 3-2 / 3$ & $40(4)$ & $30(2)$ \\
$>2 / 3$ & $9(2)$ & $2(0)$
\end{tabular}


narrower and displaced laterally in the hindlimb (Bischofberger et al. 2006). Thus, our results showed good agreement between the origin of the fibres of the suspensory ligament and the location of increased radiopacity. Interestingly, the equivalent pattern of increased radiopacity was found in 15 of 60 sound horses of the control group but the opacity was only mild and diffuse.

The origin of the suspensory ligament is characterised histologically by dense collagenous connective tissue (Schramme et al. 2012). Healing of inflammatory lesions of the tendineous attachment to the bone (enthesitis) involves the formation of bone spurs, which are referred to as enthesophytes once they have reached a certain size (Ruhoy et al. 1998, Voudouris et al. 2003). It is conceivable that in the early stages of new bone formation, opacity has a vague radiographic appearance, which then progresses to a more structured pattern during the course of the disease, possibly as a result of a summation of the projections of the focal horizontal new bone formation (Fig. 2). Mildly increased radiopacity was also seen in sound control horses. This could reflect new endosteal bone formation as a result of the normal load caused by the fibres of the suspensory ligament; according to Wolf's law, bone of a healthy individual adapts to the normal load it is subjected to. We used the term increased radiopacity rather than sclerosis because the latter refers to increased hardness of bone. The increased radiopacity could represent enthesious or endosteal new bone or a combination of the two.

There were two patterns of radiopacity, one diffuse and the other multifocal. Referring to endosteal new bone formation and enthesophyte formation, diffuse increased radiopacity could represent endosteal new bone, whereas enthesophytes could be represented by multifocal increased radiopacity. This needs further investigation and remains speculative. It is not clear why multifocal radiopacity was more frequent in the hindlimbs (11 versus 6) but multifocal radiopacity was not seen in any control horse and thus could represent a pathognomonic feature of PSD.

Several authors have stated that radiographic changes are very common in horses with chronic PSD, but are rare in acute cases (Dyson 2003, Gibson et al. 2002, Gomez 2003, Ross et al. 2011). Duration of lameness was known in 103 horses, and most of these (70) had been lame for more than 28 days, which classified them as chronically lame (>28 days). Radiographic evidence of increased radiopacity was also seen in horses with a history of acute onset of lameness. The identification of mildly increased diffuse radiopacity in the proximal cannon bone of sound horses was in agreement with published information (Butler et al. 2008), but the degree of increased radiopacity was significantly higher in the PSD group. Based on the differentiation of inflammatory and non-inflammatory enthesopathies in human medicine (Voudouris et al. 2003), it is not unreasonable to expect mild radiographic changes in the proximal MCIII/MTIII of sound horses and of horses with acute onset of lameness. Because mild increased radiopacity of the proximal MCIII/MTIII may occur in sound horses, radiographs of the proximal cannon bone must be interpreted with caution.

Computed tomography has been used to evaluate horses with lameness associated with the proximal suspensory ligament
(Launois et al. 2009). This technique was superior to radiography in detecting enthesophytes and is therefore considered the gold standard of detecting new bone formation in the proximal cannon bone, be it endosteal or enthesious. However, because of lower cost and feasibility, radiography is likely to remain the primary imaging technique for the examination of horses with PSD, and CT will be used in specialised clinics.

The mean age of the horses with PSD in the present study was 10.6 years (control group $=10.1$ years); horses with forelimb suspensory desmitis were slightly younger than horses with hindlimb suspensory desmitis (10.1 versus 11.0 years). In contrast, the mean age of 155 horses with hindlimb proximal suspensory desmitis was 8.4 years, and the majority did not have radiographic changes in the cannon bone (Dyson et al. 2012). This suggests that PSD in younger horses is less likely to be accompanied by radiographic lesions. Lesions in the proximal suspensory ligament and associated increased radiopacity are caused by repetitive stress and overloading and reflect the resulting sum of degenerative processes. It is therefore logical to expect that older horses with chronic lesions are more likely to have radiographic changes in the proximal cannon bone (Mero et al. 2002, Mero et al. 2005, Ross et al. 2011).

In the present study, the proportion of jumpers (24.4\%) and dressage horses (15.1\%) was greater than that of horses used for other purposes and compared to the total hospital population (data not shown). The suspensory ligament is subject to large loads during take-off as well as landing in jumpers. Extension of the hip during hindlimb push at take-off is accompanied by hyperextension of the fetlock joint, which increases the tensile load on the suspensory apparatus (Bobbert et al. 2005). During landing, the fetlock joint undergoes severe hyperextension, which is accompanied by stress on the suspensory apparatus (Bobbert et al. 2005). It is well known that dressage horses have a high incidence of suspensory ligament problems (Dyson 2007, Murray et al. 2006, Trump et al. 2014). Since the SL is maximally loaded due to maximal extension of the fetlock joint, when during trot only one fore and hind limb is on the ground, the risk of SL desmitis may increase (Holmstrom et al. 1994, Walker et al. 2013). As shown by Riemersma et al., the mean maximal strain and mean maximal load in walk and trot is higher in the SL compared to the SDFT (Holmstrom et al. 1994, Riemersma et al. 1996, Walker et al. 2013)

The degree of lameness in horses with PSD in a fore- or hindlimb varies greatly (Dyson 2007, Genovese et al. 2011, Gibson et al. 2002). In the present study, horses with forelimb PSD had significantly lower lameness scores than horses with hindlimb PSD. It is generally more difficult for owners or trainers to recognise hindlimb lameness than forelimb lameness and therefore lameness caused by hindlimb PSD may be missed in the early stages (Dyson et al. 1995). As a result, when a horse is presented because of hindlimb proximal suspensory desmitis, the lesions at the origin of the ligament may be chronic and more pronounced than in a horse with similar forelimb lameness. Furthermore lameness attributable to the proximal suspensory ligament in hindlimbs may be exacerbated by pressure damage to the deep branch of the lateral plantar nerve, which runs in close proximity to the proximal suspensory ligament (Toth et al. 2008). 


\section{Limitations}

For complete radiographic evaluation of PSD the dorsopalmar/dorsoplantar as well as the lateromedial projections are required. In the present study the lateromedial projections were not reviewed because they were not meaningful for testing the hypothesis and assessment of increased radiopacity. Despite of this, lateromedial projections were only available in a small number of cases. Warmblood horses constituted the majority of the horses reviewed in the present study and the results may not apply to all horses of other breeds. The predominance of jumpers and dressage horses diagnosed with PSD in our study was in agreement with findings of other authors. However, a certain selection bias in the findings cannot be ruled out because our study group constituted patients of a referral hospital.

\section{Conclusions}

Comparing localization of increased radiopacity in the frontlegs and hindlegs of horses with PSD, our results showed good agreement with the anatomic origin of fibres of the suspensory ligament. Degree of increased radiopacity was significantly higher in horses with PSD but mild, diffuse increased radiopacity of the proximal MCIII/MTIII may also occur in sound horses. Multifocal radiopacity was not seen in any control horse and thus could represent a pathognomonic feature of PSD. The results of the present study aid in the interpretation of radiographic changes seen in horses with PSD. Because mild, diffuse increased radiopacity of the proximal $\mathrm{MCIII/MTIII} \mathrm{may} \mathrm{occur} \mathrm{in} \mathrm{sound} \mathrm{horses,} \mathrm{radiographs} \mathrm{of} \mathrm{the}$ proximal cannon bone of horses with suspicion of PSD must be interpreted with caution. Further studies are needed to substantiate our understanding and to refine our ability to interpretate the different radiographic changes seen in horses with PSD.

\section{References}

AAEP (1991). "Guide for verterinary service and judging of equestrian events." 4th ed.

Bischofberger A. S., Konar M., Ohlerth S., Geyer H., Lang J., Ueltschi G., Lischer C. J. (2006) "Magnetic resonance imaging, ultrasonography and histology of the suspensory ligament origin: a comparative study of normal anatomy of warmblood horses." Equine Vet. J. 38, 508-516

Bobbert M. F., Santamaria S. (2005) "Contribution of the forelimbs and hindlimbs of the horse to mechanical energy changes in jumping." Experiment. Biol. 208, 249-260

Butler J., Colles C., Dyson S. J., Kold S. (2008) The Tarsus. Clinical Radiology of the Horsel. Oxford, Wiley-Blackwell. 3rd edn.: 321-361

Dyson S. J. (1994) "Proximal suspensory desmitis in the Hindlimb: 42 Cases." Br. Vet. J. 150, 279-291

Dyson S. J. (2003) "Proximal metacarpal and metatarsal pain: a diagnostic challenge." Equine Vete. Educ. 15, 134-138

Dyson S. J. (2007) "Diagnosis and Management of Common Suspensory Lesions in the Forelimbs and Hindlimbs of Sport Horses." Clin. Tech. Equine Pract. 6, 179-188

Dyson S. J. (2011) Radiography and Radiology. Diagnosis and management of lameness in the horsel. St. Lovis, Mo., Elsevier: 168-182

Dyson S. J., Arthur R. M., Palmer S. E., Richardson D. (1995) "Suspensory Ligament Desmitis." Vet. Clin. North Am. Equine Pract. 11, 177-215
Dyson S. J., Murray R. (2012) "Management of hindlimb proximal suspensory desmopathy by neurectomy of the deep branch of the lateral plantar nerve and plantar fasciotomy: 155 horses (20032008)." Equine Vet. J. 44, 361-367

Genovese R. L., Dyson S. J. (2011) The Suspensory Apparatus. Diagnosis and Management of Lameness in the Horsel. St. Lovis, Missouri, Saunders: 738-760

Gibson K. T., Steel C. M. (2002) "Conditions of the suspensory ligament causing lameness in horses." Equine Vet. Educ. 14, 39-50

Gomez J. H. (2003) "Proximal suspensory desmitis in the hind limb." Proceedings The North American Veterinary Conference, Large Animal; Gainsville FL, 148-149

Holmstrom M., Fredricson I., Drevemo S. (1994) "Biokinematic differences between riding horses judged as good and poor at the trot." Equine vet. J. Suppl. 17, 51-56

Kold S. E., Dyson S. J. (2011) Lameness in the Dressage Horse. Diagnosis and Management of Lameness in the Horsel. St. Lovis, Missouri, Elsevier: $1112-1123$

Launois M. T., Vandeweerd J. M., Perrin R. A., Brogniez L., Desbrosse F. G., Clegg P. D. (2009) "Use of computed tomography to diagnose new bone formation associated with desmitis of the proximal aspect of the suspensory ligament in third metacarpal or third metatarsal bones of three horses." J. Am. Vet. Med. Assoc. 234, 514-518

Mero J., Pool R. (2002) Twenty cases of degenerative suspensory desmitis in Peruvian Paso horses. Proc. Am. Assoc. Equine Pract., Orlando, 48:329-334

Mero, J. L. and Scarlett, J. M. (2005). "Diagnostic criteria for degenerative suspensory ligament desmitis in Peruvian Paso horses." Equine Vet.Sci. 25, 224-228

Murray R. C., Dyson S. J., Tranquille C., Adams V. (2006). "Association of type of sport and performance level with anatomical site of orthopaedic injury diagnosis." Equine Vet. J. Suppl. 36, 41 1-416

Nagy A., Dyson S. J. (2009) "Magnetic resonance anatomy of the proximal metacarpal region of the horse described from images acquired from low- and high-field magnets." Vet. Radiol. Ultrasound. 50, 595-605

Riemersma D. J., van den Bogert A. J., Jansen M. O., Schamhardt H. C. (1996) Tendon strain in the forelimbs as a function of gait and ground characteristics and in vitro limb loading in ponies. Equine Vet. J. 28, 133-138

Ross M. W., Dyson S. J. (2011). Lameness in the Dressage Horse in: Diagnosis and management of lameness in the horsel. St. Lovis, Mo., Elsevier/Saunders

Ross M. W., Dyson S. J. (2011) The Suspensory Apparatus in: Diagnosis and management of lameness in the horsel. St. Lovis, Mo., Elsevier/Saunders

Ruhoy M. K., Schweitzer M. E., Resnick D. (1998) Enthesopathy. Rheumatologyl. J. Klippel and Dieppe P. London, Mosby. 2nd ed.

Schramme M., Josson A., Linder K. (2012) "Characterization of the origin and body of the normal equine rear suspensory ligament using ultrasonography, magnetic resonance imaging, and histology." Vet. Radiol. Ultrasound 53, 318-328

Toth F., Schumacher J., Schramme M., Holder T., Adair H. S. Donnell R. L. (2008) "Compressive damage to the deep branch of the lateral plantar nerve associated with lameness caused by proximal suspensory desmitis." Vet. Surg. 37, 328-335

Trump M., Fürst A., Theiss F. (2014). A retrospective study of the prevalence of injuries to the suspensory ligament, digital flexor tendons and associated structures in a non-racehorse referral-hospital population. Diss. Med. Vet. Zurich

Voudouris K. P., Sidiropoulos P., Vounotripidis P., Arvanitakis M. (2003) "Enthesial fibrocartilage - bone interaction: a radiographic study of selected sites of nonsynovial peripheral enthesopathy." J. Musculoskelet. Neuron. Interact. 3, 89-100

Walker V. A., Walters J. M., Griffith L., Murray R. C. (2013) "The effect of collection and extension on tarsal flexion and fetlock extension at trot." Equine Vet. J. 45, 245-248

Zauscher J. M., Estrada R., Edinger J., Lischer C. J. (2013) "The proximal aspect of the suspensory ligament in the horse: How precise are ultrasonographic measurements?" Equine Vet. J. 45, 164-169 